\title{
The Application of Active and Passive Remote Sensing Data for Drought Detection
}

\author{
A Sediyo Adi Nugraha ${ }^{1}$, I Putu Ananda Citra ${ }^{1}$ \\ adi.nugraha@undiksha.ac.id \\ ${ }^{1}$ Universitas Pendidikan Ganesha, Indonesia
}

\begin{abstract}
This study aims to find out how to detect drought by examining distribution using active and passive sensors. Active sensors use Sentinel 1-A and RGB composites as a drought detection approach combined with vegetative indices. The passive sensors use Landsat 8 OLI/TIR with the TVDI method and emphasize the surface temperature and vegetation index. The results showed that active sensors with RGB Composites could distinguish drought conditions even with conspicuous residential areas. Whereas passive sensors with TVDI clearly show the propagation of drought. The TVDI itself is performed by knowing the relationship between surface temperature and vegetation index where the results indicate a high association of 0.99 and 0.97 . It suggests that the 1-A sentry still needs a unique algorithm to identify droughts compared to Landsat.
\end{abstract}

Keywords: Landsat 8 OLI/TIRS, Sentinel 1-A, Drought, LST, TVDI

\section{Introduction}

Drought is an ongoing disaster in Indonesia during the dry season. The impact of drought can cause several other catastrophic events such as wildfires and poor harvests [1]. Drought surveillance is becoming essential and needs to be completed quickly and accurately. Remote sensing is an active and passive sensor-based detection and monitoring solution [2]. The use of remote sensing for drought monitoring with passive sensors has been widely done, starting from small resolution with MODIS [3]-[6] and medium resolution with Landsat [7]-[9]. In contrast to passive systems for the use of active systems in detecting drought conditions is done with soil moisture identification [10]-[12].

Active and passive sensors for remote sensing data are an essential combination because it is known that passive sensors have disadvantages with the appearance of clouds and shadows. However, active sensors will bridge these gaps and provide information on earth changes over time. Passive sensors will use Landsat imaging with the TVDI method [13], which concentrates on surface temperature and vegetation index [14]-[16]. While the sensor actively utilizes sentinel imaging 1A with the approach to vegetation display in dry and wet months [17], [18]. Different sensors for direct drought detection have been infrequent because of the limitations of remote sensing data and the applications used. They selected the two remote sensing images as data because they are freely accessible and can be optimized with algorithms that have been developed to date [19], [20].

The combination of active and passive sensors is expected to provide additional information needed for drought identification. The primary study objective was to map active and passive 
sensors and analyze differences in drought identification outcomes. The gaps and benefits of the two sensors in this study are expected to be useful for further research.

\section{Study Area and Data}

\subsection{Study Area}

The research took place at Buleleng Regency in Gerokgak Subdistrict is located on $8^{\circ} 7^{\prime} 17^{\prime}$ ' LS and 114'25'53' BT. Gerokgak district has varied topographic characteristics. The northern region has sloping conditions and is a coastal area, while in the middle is a plain area used for settlement and economic development. The southern section is entirely represented by hills dominated by structural and denudation shapes [21]. This topographical variation is becoming a significant factor of regional research because it will impact remote sensing data processing results.

\subsection{Remote Sensing Data}

Passive sensors using Landsat 8 OLI/TIRS images are freely available from the USGS website. Landsat 8 will concentrate on thermal bands to obtain drought, temperature information using Sobrino et al., [22] and vegetation index information using red and infrared bands. The step which is still performed on the passive sensors is pre-processing before entering the data processing step.

The sensor actively uses Sentinel 1-A images in dry and wet months in the same year, 2020. Sentinel 1-A images are freely available on the official Copernicus website. The acquisition of information on active sensors will concentrate on identifying the appearance of vegetation during the wet and dry months. Active sensors, the processing phase becomes very important for producing drought information.

\section{Methodology}

Figure 1 shows the steps taken to process the data in the study. The data is processed gradually using the Landsat 8 and Sentinel 1-A images.

\subsection{Land Surface Temperature (LST)}

Landsat 8 OLI/TIRS used in processing is the thermal band (band 10 and 11). The method for obtaining surface temperature data uses a method developed by Sobrino et al., [22], [23] by concentrating the emission value of the vegetation index value. Before proceeding with the LST step, a brightness temperature value must first be obtained using the method illustrated by the USGS [24] as in Equation 1.

$$
T_{\text {rad }}=\frac{K_{2}}{\ln \left(\frac{K 1}{L_{\text {sensor }}}+1\right)}
$$

Where the values $\mathrm{K}_{1}$ and $\mathrm{K}_{2}$ are the thermal bands Landsat $8 . \mathrm{L}_{\text {sensor }}$ is the resulting band of thermal radian band processing. $\mathrm{T}_{\mathrm{rad}}$ is the result of brightness temperature. Further processing is carried out to determine the surface temperature shown in equation 2. 
$\mathrm{LST}=T B_{10}+C_{1}\left(T B_{10}-T B_{11}\right)+C_{2}\left(T B_{10}-T B_{11}\right)^{2}+C_{0}+\left(C_{3}+C_{4} W\right)(1-m)+\left(C_{5}+C_{6} W\right) \Delta m$

Where $\mathrm{TB}_{10}$ and $\mathrm{TB}_{11}$ is the result of brightness temperature. $\mathrm{C} 1$ - $\mathrm{C} 6$ is a constant value derived from previous research [22], [25]-[27]. The W value is obtained from the extraction of MODIS images based on the results of the Nugraha [15]. The value of $\mathrm{m}$ and $\Delta m$ is the value of the difference in land surface emissivity in accordance with the processing of the results of Nugraha $[8]$.

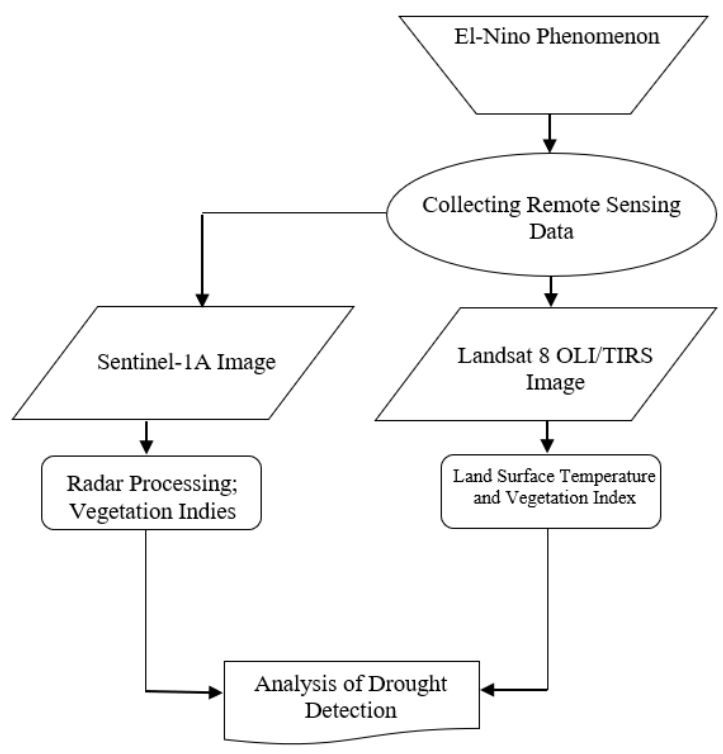

Fig. 1. Research Flowchart

\subsection{Vegetation Index}

The vegetation index used is a standard algorithm which is NDVI (Normalized Dryness Vegetation Index), shown in equation 3. NDVI information acquisition using Band 5 and Band 4 from Landsat 8 OLI image. It is used to show vegetation conditions, but the vegetation index value will be used to extract emissions values, such as the method developed by Sobrino [22] and applied by Nugraha [8]. Processing radar data for vegetation display will use several algorithms such as NDVI, SAVI (Soil Adjusted Vegetation Index), and MSAVI (Modified SoilAdjusted Vegetation Index) [28]-[30] it was used to find out whether there are differences that arise to the appearance of vegetation with different algorithms on active imagery. The results of the vegetation index will be displayed using a Red Green Blue (RGB) composite. The algorithms used by SAVI and MSAVI are presented in equations 4 and 5. The NIR is the sigma $\mathrm{VH}$, and the Red is the sigma VV on Sentinel I-A.

$$
\begin{gathered}
\text { NDVI }=\frac{\text { Band } 5-\text { Band } 4}{\text { Band } 5+\text { Band } 4} \\
\text { SAVI }=(1+L) \frac{N I R-R e d}{N I R+R+L} \\
\text { MSAVI }=(N I R+1)-\left(\frac{1}{2}\right)\left[(2 N I R+1)^{2}-8(N I R-R)\right]^{1 / 2}
\end{gathered}
$$




\subsection{Temperature Vegetation Dryness Index (TVDI)}

Sandholt et al. [13] developed the TVDI method to monitor drought. The use of this method makes it possible to compare the surface temperature with the vegetation index to determine the condition of an area experiencing a drought. The value produced by TVDI starts from the range of values 0 to 1 , where the value of 0 is wet conditions and the value of 1 is a dry condition [4], [13], [31]. The TVDI algorithm is shown in equation 6.

$$
\text { TVDI }=\frac{L^{2 S T}-L_{S T} \min }{a+b N D V I-L S T_{\min }}
$$

Where LST is a surface temperature, the $\mathrm{LST}_{\min }$ value represents the lowest surface temperature in the treatment. Equation a+bNDVI results from the regression obtained by the connection between the surface temperature and the vegetation index.

\section{Result and Discussion}

Landsat imagery using the TVDI method shows the distribution of drought-affected areas in Figure 3. Areas with hilly topography to approach the plains are primarily included in the wetness, Normal, and Slight Drought classes. In comparison, drought conditions are evident in plains areas dominated by built-up land. This relationship same with Sandholt et al. (2002) result has developed between surface temperature and vegetation index, where low vegetation conditions will follow high surface temperatures and instead. This studies about surface temperature and vegetation index regression results revealed a high association of 0.99 for $\mathrm{LST}_{\max }(\mathrm{a}+\mathrm{bNDVI})$ and 0.97 for $\mathrm{LST}_{\min }$.

The Gerokgak area has a landform character dominated by structural forms with textured soil conditions in the sand [32]. Therefore, the Gerokgak region tends to experience drought first compared to other regions in Bali province. The results of field survey activities and accuracy tests showed that hilly areas bordered by plains tended to be more rock and did not show the presence of thick soil solums. In addition, accuracy tests conducted with a soil moisture tester has a good relation on severe and moderate drought showed a value of 1 , while a wet and normal region in a high-vegetation area showed a value of 8 . The tools can provide measurements only 5 centimetres from the ground. Based on the 50 samples taken, measurements based on class distribution obtained an accuracy of $84 \%$, where the difference in accuracy occurred in regular classes that entered the dry class. The accuracy only for the Landsat processing and for Sentinel-1A it is difficult to seen because information mostly about speard of built-up. If built-up is particulary from drought mapping, so the accuracy Sentinel is more lower than Landsat. 


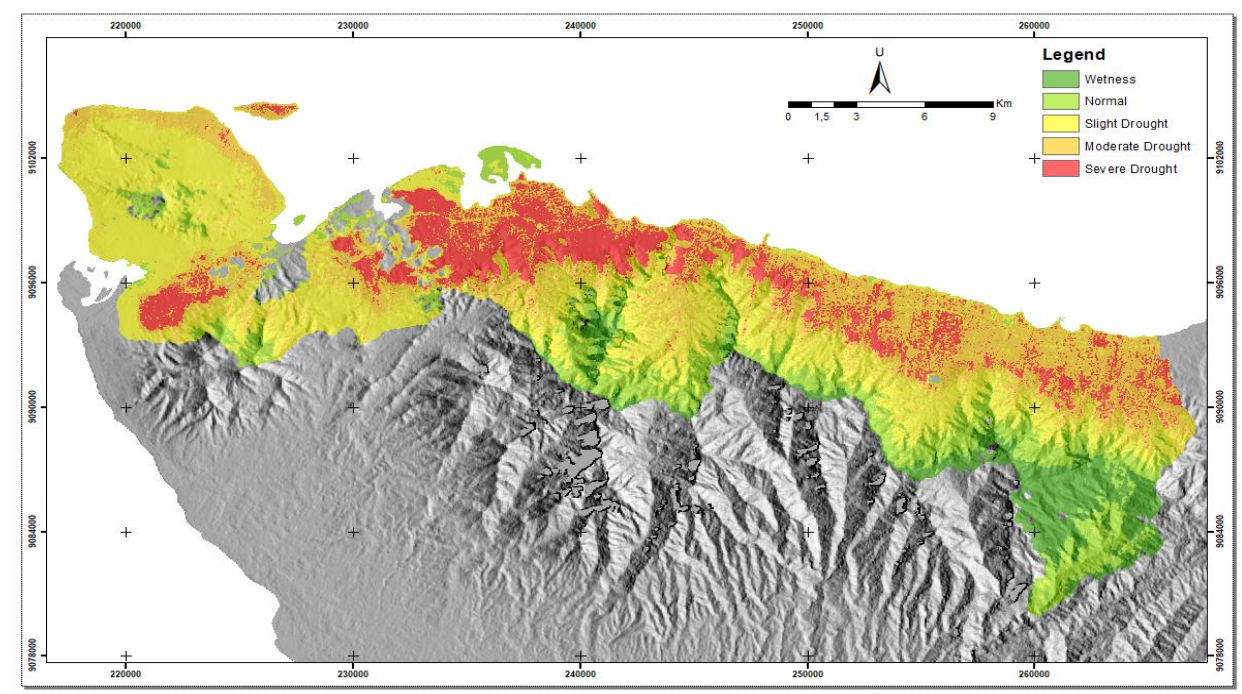

Fig. 3. TVDI Result

Sentinel 1-A in drought identification made with a composite colour (RGB) approach in which the inputs used are vegetation index and sigma VH and VV. This approach carrie out considering sentinel 1-A imaging capable of using all channels ( VV $+\mathrm{VH}$ ) possessed. The resulting RGB composite makes a difference during the wet and dry seasons. The dry season is in July, with the wet season in November. RGB patterns with SAVI/MSAVI composites in red bands, sigma VV in green bands, and sigma VH on blue bands (Figure 4a) show sensitivity to building appearances, and vegetation appearances tend to be dark in colour. The second RGB pattern with the NDVI composite on the red band, the sigma VV on the green band, and the sigma VH on the blue band (Figure $4 \mathrm{~b}$ ) show a brighter water display with red colour gradations to yellow and orange, indicating the appearance of the building. The appearance of the vegetation dominate by the spotty red aspect mixed with the black.

The third composite (Figure 4c) addresses drought by focusing on the red and green bands that use the VV and VH sigma bands. As for the blue band using the appearance of SAVI / MSAVI. These composites show more colour differences which are easily classified between vegetation and soil. The appearance of the vegetation is represented in purple colour in the dark direction, whilst for the appearance of a light purple building. The appearance of an open field shows a darker colour on the moist moon and dark green on the dry moon. Knowing the difference in each colour composite resulting from the vegetation index and Sentinel 1-A channel proves that with composites, vegetation and non-vegetation conditions are still able to be distinguished even though the limits are still unclear. 
Dry Month

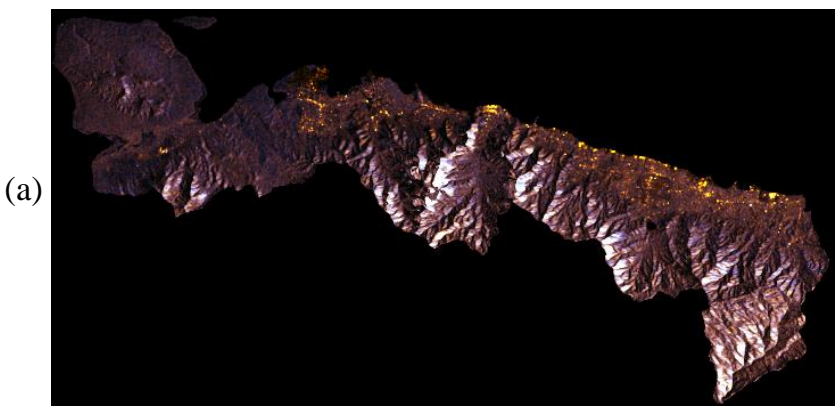

(b)

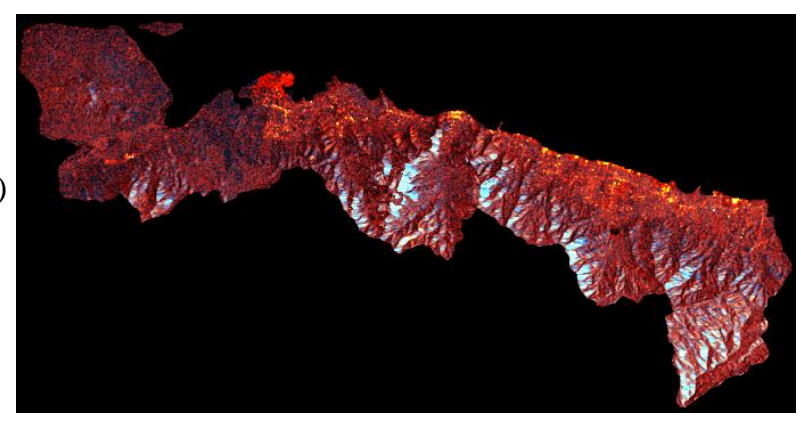

(c)

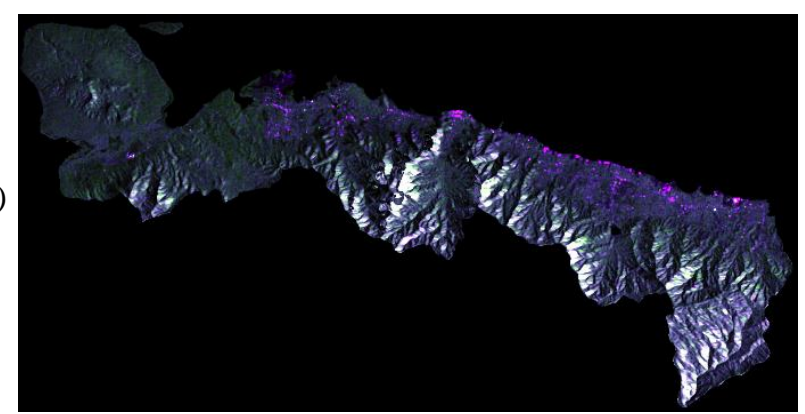

Wet Month
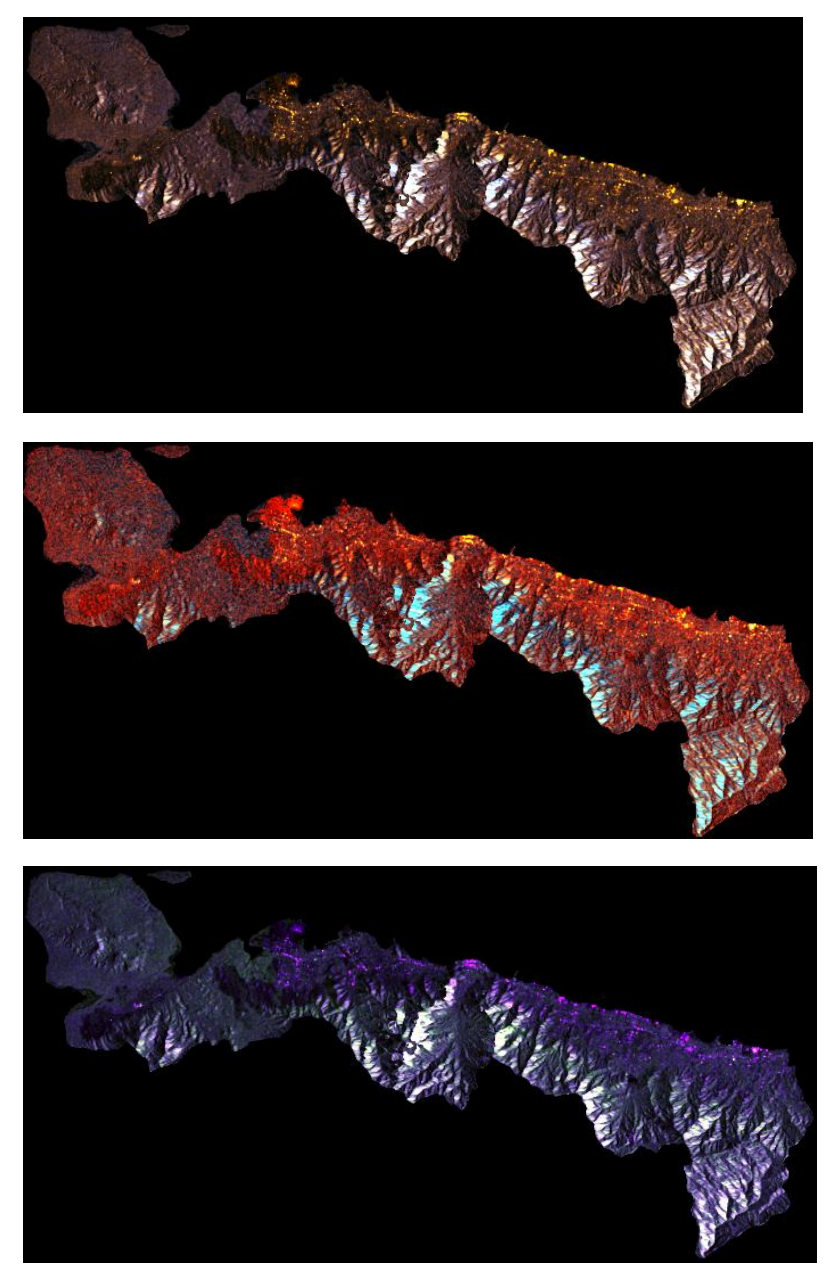

Fig. 4. RGB Composite of Sentinel 1-A; (a) SAVI/MSAVI, VV, VH (b) NDVI, VV, VH (c) VV, VH, SAVI/MSAVI 
Landsat 8 OLI/TIR and Sentinel 1-A images show differences in drought identification. Passive sensors like Landsat require clear steps and measurable variables to identify drought. In contrast, Sentinal 1-A uses a simple method with colour composites and has a similar model to the TVDI results. On the plains, one sees more clearly the combination of composites against the spread of drought with TVDI than on the hills. Both are sensitive to the appearance of buildings because most of them use clay and iron roofs.

\section{Conclusion}

The spread of drought resulting from RGB composite images on Sentinel 1-A that uses vegetation indexes and $\mathrm{VV}+\mathrm{VH}$ is still not strong enough to indicate the location of drought in a region. In contrast to Landsat, which uses the TVDI method, the location of the drought distribution, especially in the plains, is clearly and reliably shown. The image capability of Sentinel 1-A in drought identification is still necessary for unique algorithms to enhance VV + VH channels. Conversely, in the case of the TVDI method, it is necessary to record the relationship between the surface temperature and the vegetation index. In future studies, the use of Sentinel 1-A expect to provide specific algorithms for detecting drought.

\section{References}

[1] A. S. Suryani, “ancaman EL NINO 2015,” INFO Singkat, vol. VII, no. 13, pp. 9-12, Jul. 2015.

[2] Y. Zhou et al., "The potential of active and passive remote sensing to detect frequent harvesting of alfalfa," Int. J. Appl. Earth Obs. Geoinf., vol. 104, no. January, p. 102539, 2021, doi: 10.1016/j.jag.2021.102539.

[3] A. S. A. Nugraha, T. Gunawan, and M. Kamal, "Downscaling land surface temperature on multi-scale image for drought monitoring," in Sixth Geoinformation Science Symposium, 2019, no. November, p. 6, doi: 10.1117/12.2544550.

[4] N. T. Son, C. F. Chen, C. R. Chen, L. Y. Chang, and V. Q. Minh, "Monitoring agricultural drought in the lower mekong basin using MODIS NDVI and land surface temperature data," Int. J. Appl. Earth Obs. Geoinf., vol. 18, no. 1, pp. 417-427, 2012, doi: 10.1016/j.jag.2012.03.014.

[5] D. Dutta, A. Kundu, N. R. Patel, S. K. Saha, and A. R. Siddiqui, "Assessment of agricultural drought in Rajasthan (India) using remote sensing derived Vegetation Condition Index (VCI) and Standardized Precipitation Index (SPI)," Egypt. J. Remote Sens. Sp. Sci., vol. 18, no. 1, pp. 53-63, 2015, doi: 10.1016/j.ejrs.2015.03.006.

[6] L. Du et al., "A comprehensive drought monitoring method integrating MODIS and TRMM data," Int. J. Appl. Earth Obs. Geoinf., vol. 23, no. 1, pp. 245-253, 2013, doi: 10.1016/j.jag.2012.09.010.

[7] A. S. A. Nugraha, T. Gunawan, and M. Kamal, "Comparison of Land Surface Temperature Derived from Landsat 7 ETM+ and Landsat 8 OLI/TIRS for Drought Monitoring," IOP Conf. Ser. Earth Environ. Sci., vol. 313, no. 1, pp. 0-10, 2019, doi: 10.1088/1755-1315/313/1/012041.

[8] A. S. A. Nugraha and D. M. Atmaja, "Split-windows algorithm (swa) methods using fractional vegetation cover (fvc) on landsat 8 oli/tirs," IOP Conf. Ser. Earth Environ. Sci., vol. 683, no. 1, 2021, doi: 10.1088/1755-1315/683/1/012107.

[9] H. Adiwicaksono, Sudarto, and Widianto, "Estimasi distribusi spasial kekeringan lahan 
di kabupaten tuban menggunakan penginderaan jauh dan sistem informasi geografis," J. Tanah dan Sumberd. Lahan, vol. 1, no. 2, pp. 70-76, 2014.

[10] B. Bauer-Marschallinger et al., "Soil moisture from fusion of scatterometer and SAR: Closing the scale gap with temporal filtering," Remote Sens., vol. 10, no. 7, pp. 1-26, 2018, doi: 10.3390/rs10071030.

[11] M. Urban et al., "Surface moisture and vegetation cover analysis for drought monitoring in the southern Kruger National Park using Sentinel-1, Sentinel-2, and Landsat-8," Remote Sens., vol. 10, no. 9, 2018, doi: 10.3390/rs10091482.

[12] Q. Wang et al., "Comparative Analysis of Landsat-8, Sentinel-2, and GF-1 Data for Retrieving Soil Moisture over Wheat Farmlands," Remote Sens., vol. 12, no. 2708, pp. $1-6,2020$.

[13] I. Sandholt, K. Rasmussen, and J. Andersen, "A simple interpretation of the surface temperature/vegetation index space for assessment of surface moisture status," Remote Sens. Environ., vol. 79, no. 2-3, pp. 213-224, 2002, doi: 10.1016/S00344257(01)00274-7.

[14] A. S. A. Nugraha and D. M. Atmaja, "Pemanfaatan Citra Penginderan Jauh MultiTemporal Penggunaan Lahan Di Kabupaten Buleleng ( The Application of MultiTemporal Remote Sensing Images to Detect Urban Heat Island ( UHI ) for Land use Changes in Buleleng District )," Maj. Ilm. Globe, vol. 22, no. 2, pp. 71-82, 2020.

[15] A. S. Adi Nugraha, "Pemanfaatan Metode Split-Windows Algorithm (Swa) Pada Landsat 8 Menggunakan Data Uap Air Modis Terra," Geomatika, vol. 25, no. 1, p. 9, 2019, doi: $10.24895 /$ jig.2019.25-1.877.

[16] A. S. A. Nugraha and I. P. A. Citra, "Perbandingan Metode Soil Adjusted Vegetation Index ( SAVI ) dan Forest Canopy Density ( FCD ) untuk Identifikasi Tutupan Vegetasi," Geografi, vol. 18, no. 11, pp. 1-8, 2021, doi: 10.15294/jg.v18i1.25367.

[17] D. D. Alexakis, F. D. K. Mexis, A. E. K. Vozinaki, I. N. Daliakopoulos, and I. K. Tsanis, "Soil moisture content estimation based on Sentinel-1 and auxiliary earth observation products. A hydrological approach," Sensors (Switzerland), vol. 17, no. 6, pp. 1-16, 2017, doi: 10.3390/s17061455.

[18] Q. Gao, M. Zribi, M. J. Escorihuela, and N. Baghdadi, "Synergetic use of sentinel-1 and sentinel-2 data for soil moisture mapping at $100 \mathrm{~m}$ resolution," Sensors (Switzerland), vol. 17, no. 9, 2017, doi: 10.3390/s17091966.

[19] M. Shiran, P. Mozzi, H. Adab, and M. A. Zangeneh Asadi, "Remote sensing assessment of changes of surface parameters in response to prolonged drought in the arid zone of central Iran (Gavkhoni playa)," Remote Sens. Appl. Soc. Environ., vol. 23, no. November 2020, p. 100575, 2021, doi: 10.1016/j.rsase.2021.100575.

[20] H. Zhao, Y. Li, X. Chen, H. Wang, N. Yao, and F. Liu, "Monitoring monthly soil moisture conditions in China with temperature vegetation dryness indexes based on an enhanced vegetation index and normalized difference vegetation index," Theor. Appl. Climatol., vol. 143, no. 1-2, pp. 159-176, 2021, doi: 10.1007/s00704-020-03422-x.

[21] BPS Kabupaten Buleleng, "Badan Pusat Statistik Kabupaten Buleleng," 2021. https://bulelengkab.bps.go.id/statictable/2015/09/21/23/letak-geografis-kabupatenbuleleng.html (accessed Aug. 18, 2021).

[22] J. A. Sobrino, J. El Kharraz, and Z. L. Li, "Surface temperature and water vapour retrieval from MODIS data," Int. J. Remote Sens., vol. 24, no. 24, pp. 5161-5182, 2003, doi: 10.1080/0143116031000102502.

[23] J. A. Sobrino et al., "Land surface emissivity retrieval from different VNIR and TIR sensors," IEEE Trans. Geosci. Remote Sens., vol. 46, no. 2, pp. 316-327, 2008, doi: 
10.1109/TGRS.2007.904834.

[24] Department of the Interior U.S. Geological Survey, "Landsat 8 Data Users Handbook," $2016 . \quad$ [Online].

Available:

https://landsat.usgs.gov/documents/Landsat8DataUsersHandbook.pdf.

[25] J. A. Sobrino, Z. L. Li, M. P. Stoll, and F. Becker, "Multi-channel and multi-angle algorithms for estimating sea and land surface temperature with atsr data," Int. J. Remote Sens., vol. 17, no. 11, pp. 2089-2114, 1996, doi: 10.1080/01431169608948760.

[26] S. Zhao, Q. Qin, Y. Yang, Y. Xiong, and G. Qiu, "Comparison of two split-window methods for retrieving land surface temperature from MODIS data," J. Earth Syst. Sci., vol. 118, no. 4, pp. 345-353, 2009, doi: 10.1007/s12040-009-0027-4.

[27] D. Skokovic et al., "Calibration and Validation of land surface temperature for Landsat8- TIRS sensor TIRS LANDSAT-8 CHARACTERISTICS,” L. Prod. Valid. Evol. ESA/ESRIN, p. 27, 2014, doi: 10.1063/1.452862.

[28] J. W. Rouse et al., "Monitoring Vegetation Systems in the Great Plains with ERTS," in 3rd ERTS-1 Symposium, 1974, pp. 309-317, [Online]. Available: https://ntrs.nasa.gov/search.jsp?R=19740022614.

[29] A. Huete, "A soil-adjusted vegetation index (SAVI)," Remote Sens. Environ., vol. 25, no. 3, pp. 295-309, 1988, doi: 10.1016/0034-4257(88)90106-X.

[30] J. Qi, A. Chehbouni, A. R. Huete, Y. H. Kerr, and S. Sorooshian, "A modified Soil Adjusted Vegetation Index," Remote Sens. Environ. - Remote SENS Env., vol. 48, pp. 119-126, 1994.

[31] C. Wang, S. Qi, Z. Niu, and J. Wang, "Evaluating soil moisture status in China using the temperature-vegetation dryness index (TVDI)," Can. J. Remote Sens., vol. 30, pp. 671-679, 2004.

[32] D. Wahyuni, I. Sukarsa, and A. S. Nugraha, "The Role of Geomorphological Maps in Regional Planning and Management in Indonesia (Case: Buleleng Regency, Bali)," in ICLSSE 2020, 2021, doi: 10.4108/eai.10-11-2020.2303362. 